\title{
Micro-Modeling Brick Walls with Reinforced Openings by a Layer of Shotcrete
}

\author{
Seyed Abdolreza Hashemizadeh ${ }^{1} \&$ Leila Shahryari $^{2}$ \\ ${ }^{1}$ Department of Civil Engineering, Islamic Azad University, Taft branch, Taft, Iran \\ ${ }^{2}$ Department of Civil Engineering, Islamic Azad University, Shiraz Branch, Shiraz, Iran \\ Correspondence: Leila Shahryari, Department of Civil Engineering, Islamic Azad University, Shiraz Branch, \\ Shiraz, Iran. E-mail: Lshahryari@iust.ac.ir
}

Received: June 19, 2016

Accepted: July 3, 2016

Online Published: March 29, 2017

doi:10.5539/mas.v11n4p103

URL: https://doi.org/10.5539/mas.v11n4p103

\begin{abstract}
In this paper, the numerical and experimental results related to masonry walls with and without reinforcing cover layer of reinforced concrete (shotcrete) have been validated. Then, by numerical modeling and reviewing and conducting parametric studies on brick walls, the effect of the parameters affecting the behavior of these walls has been investigated. We found that the studied unreinforced masonry walls with 4 times increased in vertical stress improved the maximum strength of the sample by 2.15 times. Pod and layer of shotcrete significantly increased the lateral capacity and formability of brick walls. In samples with opening because of opening in reinforced or non-reinforced samples with shotcrete, the final capacity of samples was reduced and failure mode is changed.
\end{abstract}

Keywords: masonry walls, existence of opening in the masonry walls, numerical studies, shotcrete

\section{Introduction}

Unreinforced masonry (URM) buildings are common in many countries because of easy access to materials, ease of construction methods, and economic reasons, especially for constructing residential houses. However, the heavy destruction of the buildings in the Kocaeli earthquakes in Turkey in 1999 and the Bam earthquake in Iran in 2003 showed that this type of building is vulnerable. Therefore, improving the existing masonry buildings with respect to construction principles is very important. In Iran in between types of methods for strengthening masonry structures because of the simplicity and economical nature of implementation of the shotcrete compared with other methods, as well as the majority of existing building structures in Iran are residential, maintaining their existing view is not very important. Using shotcrete is very popular so that about $90 \%$ of strengthening of masonry structures is done using shotcrete. However, due to the lack of sufficient research on masonry buildings, the strengthening method and details of these structures is person-dependent without any certain computational method (Hashimoto et al., 2014). Regarding the behavior of masonry walls with and without reinforcement with a layer of shotcrete, Paige was the first who used micro-modeling for masonry structures. He modeled bricks by continuous elastic elements that were covered by the surface elements (Page, A.W., 1978). Based on the characteristics of cement between the bricks and taking into account a characteristic equation of bricks, Gambaruta and Lagumarsio (Gambarotta and Lagomarsino, 1997) designed a composite model and applied it for finite element analysis of lateral movement of brick shear walls. Also in 1996, Alcocer et al examined the behavior of masonry walls having pod by Bar grid and cover cement. They concluded that the initial stiffness of reinforced samples was about $67 \%$ of the sample without reinforcing. However, the percentage of reinforcement shotcrete steel grid had little effect on initial hardness of the reinforced samples. These experiments showed that by reinforcing the wall using shotcrete, we can increase the shear strength and formability capacity. Also the strength of shotcrete walls depends on the percentage of reinforcement steel mesh and cement quality (Alcocer, Ruiz, Pineda and Zependa, 1996). In 2007, Abrams built 8 foundation masonry walls and experiments were conducted by applying cycle displacements on the samples. The results of reinforced walls with shotcrete showed that by increasing the amount of relative displacement, the walls were isolated from the base location and rocking failure occurred in it. Also, the implementation of shotcrete on the masonry wall increased the energy dissipation system as well as the hardness and strength (Abrams, Smith, Lynch and Franklin, 2007).

In this paper, first, the numerical results with experimental results related to masonry walls with and without 
reinforcing cover layer of reinforced concrete (shotcrete) have been validated and we studied the effects of time, gravity, creating the confinement conditions by concrete having pod, openings on masonry walls without reinforcement, improving the masonry walls with a layer of shotcrete, the effect of shotcrete layer bar, strengthening with shotcrete on the wall and existence of opening on improved walls using numerical modeling and parametric studies and studies on brick walls(Keykhah and Dadadshzadeh, 2017 ).

\section{Importance of Studying the Brick Buildings}

The importance of studying the brick buildings is examinable and considerable from two aspects which are mentioned below:

- Statistics from past earthquakes and brick building performance in recent earthquakes.

- Status of masonry buildings (brick) in constructions.

\section{Modeling Brick Structures}

In order to analyze the brick structures, the behavior and geometry of the structure should be idealized. Idealization of behavior includes selection of behavioral models and type of analyzes, and geometric idealization include the modeling of brick structures or desired elements. Idealization of behavior brick structures includes the selection of structure analysis method and the curve of material behavior. Typically, for the analysis of brick structures, behaviors such as elastic behavior, plastic behavior of nonlinear behavior are considered. Nonlinear the analysis of is the most powerful method to estimate the response and structure behavior from the linear range to cracking and complete disruption.

For modeling the materials of brick structures there are some problems, the most important of which areas follows:

1) Implementation of brick structures can be very different.

2) The characteristics of bricks differ from mortars; bricks are harder.

3) Brick dimensions are limited compared to mortars.

4) The hardness of vertical mortars is much less than horizontal ones.

Modeling of brick structures can be divided into two general categories, namely micro-modeling and gross-modeling.

\subsection{Crack Propagation Modeling}

For modeling crack, two ideas of separate crack and broadcast cracks should be considered.

In the ideas of separate cracks, geometry and grid (or mesh?) finite element varies with crack border and elements surrounded by cracks, generally assumed to be elastic. High volume and time calculations limit its application. The idea of broadcast cracks has more applications because of fewer calculations compared with separate cracks. However, in the quasi-brittle materials such as bricks and concrete, one or more cracks both in length and in depth expand generally until the structure is destroyed. The idea of broadcast cracks shows the more appropriate response, in the any structure that cracks have almost uniform distribution. For example, in reinforced concrete or reinforced masonry, the cracks have almost uniform distribution. Broadcast cracks are created in a limited area and it models propagation of cracks averagely. But cracks of separate models describe certain cracks whose location is previously determined, and this means that estimating the place and the direction of cracks is very important in this method and if this estimate is not correct, the results will not have acceptable accuracy. Based on the advantages and disadvantages of each of the above methods, It seems that the combined use of both methods (separate and broadcast cracks) gives acceptable results with appropriate accuracy. Therefore in this paper, for modeling the masonry walls, we used the combination of both mentioned methods.

\subsection{Modeling Method}

For modeling, we used both methods of broadcast cracks and separate cracks. Concrete elements are modeled using the continuous elements by method of broadcast cracks (Okamura and Maekawa, 1991). and simplified micro-modeling proposed by Lourenco is used to model the wall. Lorenzo modeled masonry units (brick) in the continuous elements in 1997 (Lourenco, 1994) whereas the connection elements and potential cracking unit were modeled connection elements with zero thickness (Figure 1). Contact elements, including all failure mechanisms, such as cracking at the junction, slip on the horizontal and vertical junction, cracking in the units in the case of direct tension, cracking of diagonal tension of masonry units and sliding units at stretch due to dilatancy of mortar were considered as high levels of stress. Contact elements are used to evaluate the risk of detachment among the various components of the analytical samples. For example, according to the available laboratory 
results as well as damages in past earthquakes, it turn out that joints especially the contact masonry walls and coils and pod connection to the foundation have the most possible detachment; therefore, contact elements are used in these places. For modeling the behavior of opening sliding of contact elements, we use the modified model contact density developed by Ghiassi et al. (Ghiassi, Soltani, and Tasnimi, 2012). for interface of mortar with brick.

\section{Validation of Numerical Models by Laboratory Samples}

\subsection{Experiments Conducted in Tehran University (Darbhanzi, Marefat and Khanmohammadi, 2014)}

A comprehensive study was done in 2014 on the set of the masonry walls at Tehran University in Iran. Here, one of the examined laboratory samples has been studied. This sample has a length of $270 \mathrm{~cm}$, height of $140 \mathrm{~cm}$ and thickness of $16 \mathrm{~cm}$ with an axial and mortar shear stress of stress of $1 \mathrm{Kg} / \mathrm{cm}^{2}$ and $2 \mathrm{Kg} / \mathrm{cm}^{2}$, respectively. Until the formation of sliding failure mode, resistance in the sample was increased and by starting a slide mechanism with uplift (after resistance $4.37 \mathrm{KN}$ ) in the wall, resistance of the sample was almost constant and its loss was low. In figure 2, the behavior curve of laboratory and analytical samples has been compared and figure 3 shows the comparison between the pattern of cracking in laboratory and numerical examples. As shown, the schematic model of dominant failure mode in numerical models and laboratory samples are similar and it is a sliding with uplift.

\subsection{Experiment by Abrams (Abrams, Smith, Lynch and Franklin, 2007).}

To control and compare the effect of different strengthening methods on the capacity and plasticity of brick bases, Abrams et al. strengthened and tested brick bases (figure 4) in different methods. Analytical sample of unreinforced base (sample F1) and sample reinforced by cap concrete (samples F4) were constructed and compared with experimental results (figure 5).

\subsection{Experiments Conducted by Yaghoobifar (Jaghoobifar, 2008)}

Yaghoobifar evaluated a set of masonry walls and tested the behavior of reinforced brick walls with reinforced concrete cover in 2008. Here, some of his laboratory samples are discussed. SSBW (should be spelled out first) samples is the walls reinforced by one sided concrete spraying and DSBW (should be spelled out first) samples of the walls reinforced by two-sided spraying concrete. Axial force applied on the SSBW2 and DSBW2 was 6 tons and axial force applied on the SSBW1 and DSBW1 was 4 tons. The mean compressive strength building materials was also $10 \mathrm{MPa}$.

\section{- SSBBW1 Sample}

Figure 6 shows the schematic cracking model of the sample at the end of the experiment and schematic model of deformation numerical models. As shown, the schematic cracking model was almost similar in the both samples. So that in both samples, cracks occurred at the junction of wall-to-foundation at the end failure mode of uplift mode was dominant on the sample. Also, figure 7 shows the envelope of experimental and numerical samples in terms of displacement. As shown, the displacement rate is equival to the maximum capacity and the behavior of two experimental and numerical samples in softening state have relatively good compliance. However, the initial stiffness and final capacity of the numerical model were more than those of the laboratory samples.

\section{- DSCW1 samples}

Figure 9 shows schematic cracking model of the samples at the end of the experiment and schematic model of deformation in the numerical model. According to this figure, schematic model of cracking is almost similar in the both samples. So that in both samples cracks occurred at the junction of wall-to-foundation at the end failure mode of uplift mode was dominant on the sample. Also figure 8 shows the envelope of experimental and numerical samples in terms of displacement. This figure shows that the displacement rate is equival to the maximum capacity and the behavior of two experimental and numerical samples in softening state have relatively good compliance. However, the initial stiffness and final capacity of the numerical model are more than those of the laboratory samples.

\section{- $\quad$ SSBW2 and DSBW2 samples}

Figure 10 shows the schematic cracking model of the samples at the end of the experiment and schematic model of deformation in the numerical model. So that in both samples diagonal failure mode was the dominant mode on the sample. In the numerical model, the schematic model of deformation of the samples was determined by changes in elements of cover layer of reinforced concrete. Figure 11 shows the envelopes of experimental SSBW2 and DSBW2 samples and their corresponding numerical model in terms of displacement. As shown, the samples SSBW2 final capacity, displacement corresponding to the maximum resistance and the behavior of two 
experimental and numerical samples in a state of softening and in the DSBW2, the final capacity rate and the behavior of both numerical and experimental samples in softening state had relatively good compliance. But the initial hardness in the numerical analyzes were more than those of experimental samples.

\section{Parametric Studies on the Unreinforced Masonry Brick Walls Having Pod}

\subsection{Modeling Reference Samples}

In order to conduct parametric studies RMW1, the control model was modeled as figure 12a. This sample is as a reference sample in the following research. To save time, 0.7 dimensional scales are used for modeling. Its length, height and thickness are 280,170 and $21 \mathrm{~cm}$ respectively on which lays a concrete beam with concrete with compressive strength of $25 \mathrm{MPa}$. From a $5.2 \mathrm{~cm}$ thick steel plate, lateral load is uniformly applied on the concrete beam. Vertical load of stress ratio 7.0 kilograms per square centimeter is applied on the wall. Figure $12 \mathrm{~b}$ shows that the failure of this sample is uplift form (rocking) along with mortar sliding. Figure $12 \mathrm{~b}$ shows the diagram of the capacity on RMW1samples drift to 0.8 percent drift. From the diagram and the steps of sample deformation, it is determined that the first sample cracks are made in the model in the $0.7 \mathrm{~mm}$ displacement in the first row at the junction of the wall with mortar foundation. Force applied to the samples corresponding to the first crack is $46 \mathrm{kN}$ and it is about $78 \%$ of final lateral capacity. In the drift of 0.2 percent is its maximum loading i.e. 6 tons. In the drift 4.0 percent, bearing losses occurred in the model due to smashing samples claws.

\subsection{The Effect of Gravity Load on the Behavior of Unreinforced Masonry Walls}

By creating numerical models, in this section we examined the effect of gravity load on the performance of brick walls. To conduct this study, three analytical models with characteristic and dimensions similar to reference sample (RMW1) were made. The only difference in the samples was their gravity load. Here, the walls MV1, RMW1, MV2, MV3 and MV4 had gravity loads of 0.5, 0.7, 1.1, 1.5 and 2 kilograms per square centimeter, respectively. Figure 13a shows the curve of lateral load in terms of the sample drift. According to the results obtained by increasing the vertical stress from 5.0 to 2 kilograms per square centimeter, the maximum strength of the sample is increased by 2.15 times. This high increase is related to the uplift failure mode in the samples. Also according to figure $13 \mathrm{~b}$, this strength increase is almost linear from 0.5 to 2 kilograms per square centimeter.

\subsection{The Effect of Pod on the Masonry Walls}

By creating a numerical model, in this section we examined the effect of confining by vertical and horizontal pods on the performance of brick walls. To conduct this review, an analytical model (CMW1) with characteristics and dimensions similar to numerical model of sample reference RMW1was made. The only difference in the sample is existence of pod about the masonry walls and other parameters are similar to the reference sample. According to field reports on the status of available buildings with pod, in most existing brick buildings, the percentage of longitudinal bar in the vertical pods existing is 0.5 on average $(\rho=0.005)$. In this study, in the studied model, the same percentage of bar was used to arm the pod. For this purpose, according to the scale 0.7 in the reference model RMW1, in the model having pod CMW1, to arm pod, 4 longitudinal bars with a diameter of $8 \mathrm{~mm}$ and stirrups with a diameter of $6 \mathrm{~mm}$ and with a distance of $15 \mathrm{~cm}$ in the middle and 10 $\mathrm{cm}$ in the $45 \mathrm{~cm}$ on the abutments are used. The width of vertical and horizontal pods was $20 \mathrm{~cm}$ and their thickness proportional to the thickness of the model was about $21 \mathrm{~cm}$. To determine the distances of stirrups relative to each other, in the horizontal and vertical pods, minimum customer scaling of the code 2800 relating to the pods were used in this the model. Pod concrete strength in the model was considered to be $25 \mathrm{MPa}$.

Figure 14a shows the comparison of the load-drift curves of RMW1 and CMW1 samples. As shown, the deformation of the CMW1 sample, at the beginning of the experiment, and the behavior of the sample was linear elastic. In the drift 0.042 , the percentage of load equivalent to $114 \mathrm{kN}$, by making sliding cracks on the sixth horizontal row of the walls, nonlinear step in the sample began. Then, by continuing loading on drift 0.12 , the percent of the model attained its maximum capacity i.e. $167 \mathrm{kN}$. According to the comparison of the two curves, capacity and area under the curve in the CMW1 model were respectively about 2.78 and 2.6 times more than those of the RMW1 sample. This increase in the strength and area under the curve shows the significant effect of pod on increasing the lateral capacity and formability of brick walls. Figure $14 \mathrm{~b}$ shows how the walls with pod deform.

According to this figure, schematic model of cracking in the sample having pod, was started with the sliding cracks on the sixth row from the top of the sample, whereas schematic model of failure of the reference RMW1 samples without pod was in the uplift form (rocking) with mortar sliding. 


\subsection{The Effect of the Existence of Openings in Unreinforced Masonry Walls}

The experimental results and observations of the damages to buildings after earthquakes shows that shear cracks often start from the corners of opening and extend to the central parts of the panel. Size, shape, location and details of reinforcement around openings have high effect on the performance of masonry walls. The existence of very large openings can reduce the shear capacity of masonry walls by $50 \%$ but when their area is less than $10 \%$ of the wall area, their impact on seismic performance is low (Gostic and Zarnic, 1999). Symmetric distribution of openings and using of supporting bar beneath them are important factors that can reduce the negative impact of openings (Yanez et al., 2004).

In this study, to study the effect of the existence of openings on the performance of both HMW and DHM masonry samples, respectively, windows and doors were made. Dimensions and characteristics of materials and their loads were similar to the reference RMW1 sample. It should be noted that openings around a metal frame with a respective width and thickness of 5.2 and $4 \mathrm{~cm}$ were modeled. Opening window in the BMW model was square with $80 \mathrm{~cm}$ side and in the opening; door is model DHM $60 \times 160$. Figure 15a shows how the HMW model cracks. As shown, by creating the opening, the first crack in the corner of opening occurred in sliding and diagonal form. Also, in uplift failure mode, a side of the wall act in a Pier form. In reference sample RMW1 as described in the previous section, uplift was the dominant failure mode. Figure 15b shows the comparison of force curve relative to the percent of sample drifts RMW1 and HMW. According to this figure due to opening window, the ultimate capacity of the sample decreased by $2 \%$. Also, in the samples having no opening, having the samples reached its ultimate capacity until starting sliding in the sample, in the drift is not seen 0.4 percent of drop resistance. But in the sample with opening, when drift $0.16 \%$ reaches the maximum capacity of occurrence of diagonal cracks, drop is observed in the sample. But according to the curve, with a higher drift, drop resistance severity in this curve is more in the sample without opening slides.

Figure 16a shows the cracking models DHM and RMW1. As shown, by creating the opening, failure mode is in the sliding form along with the uplifting one of the masonry piers. In the reference sample RMW1, the failure mode is uplift.

Figure 16b shows the comparison force curve relative to the percent of the samples drift RMW1 and DHM. According to this figure due to the opening door, the ultimate capacity of the samples is decreased by $25 \%$. Also in the samples having no opening, having the samples reached its ultimate capacity by starting the sliding in the sample, in the drift is observed 0.4 percent of drop resistance and in the sample with opening (DHM), resistance drop is observed in the sample drift 0.5. In general, resistance drop in the samples having no opening is more than that in the sample with opening. This is due to the created uplift failure mode in the piers around the door in the high deformations.

\section{Parametric Studies on Reinforced Brick Walls}

To evaluate the effect of the reinforcing layer of shotcrete on the behavior of masonry walls, an improved reference model, as shown in figure 17, was made and its results were compared with unreinforced reference models (RMW1 and RMW2). Then by conducting parametric studies, we evaluated the effects of the percent of reinforcing concrete layer, existing of the opening, shotcrete concrete strength and bilateral improving of the samples.

\subsection{The Effect of Reinforcing Masonry Walls with Reinforced Concrete Coating Layer}

To evaluate the effect of reinforcing masonry walls covered with a layer of reinforced concrete, model MWR1 was constructed. The sample MWR1 is the same model of the wall of the sample reference RMW1 which is reinforced by a shotcrete layer with a thickness of $5 \mathrm{~cm}$. In order to reinforce the layer of shotcrete, a grid bar with a diameter of $6 \mathrm{~mm}$ and an opening distance of $10 \mathrm{~cm}$ was used and the shotcrete grid was joint to the foundation and concrete beams (Alireza et al., 2011). Bar resistance grid and concrete strength were considered to be 2000 and $250 \mathrm{~kg}$ per square centimeters, respectively. Figure 18 shows the comparison of force curve relative to the percent of sample drifts RMW1 and MWR1. As shown, with reinforcing masonry models by concrete reinforced covering layer, the value of ultimate capacity of the sample increases by 2.4 times. Also, in the samples without reinforcing, from percent of drift 0.4 , the amount of load in the model is reduced whereas in the reinforced samples even up to $1.5 \%$ drift, high drop in the curve is not seen. This behavior shows that reinforcing the walls with shotcrete has a high effect on the performance of masonry walls.

Figure 19 shows how both samples deform. As shown, both samples deform in the uplift form.

\subsection{The Effect of Grid Reinforcement Layer of Reinforced Concrete}

In this section, to study the effect of dimensions of spring reinforced concrete cover armature grid, three 
analytical models are made, and they are compared with the results of numerical modeling of reinforced reference sample MWR1. Here, the sample PM1, PM2 and PM3 were respectively related to samples reinforced with armature grid with spring dimensions $20 \times 20,15 \times 15$ and $8 \times 8 \mathrm{~cm}$. It is noteworthy that dimensions of the source mesh grid of the analytical model of reference sample MWR1 were $10 \times 10 \mathrm{~cm}$. The diameter of bar armature grid in all samples was $6 \mathrm{~mm}$. Figure 20 shows the diagram of force against the studied drift models. According to this figure by changing the dimensions of the springs reinforced concrete grid cover in the studied area, the overall shape of the curve and their failure in the samples were similar and failure mode was in the form of uplift.

\subsection{The Effect of Dimensions of Grid Reinforcement Layer of Reinforced Concrete}

In the PM3 sample, after flowing shotcrete bars grid at the junction of wall foundation, there was no drop resistance. As a comparison between samples of PM1 and MWR1, percentage ratio of its shotcrete bar is half and its ultimate capacity is 1.4. Since no cracking was seen in the samples, it is determined that the main reason for this resistance increase is bar percent increase at the junction of cover layer of reinforced concrete with the foundation that with the uplift failure mode in the armature in this region is under tension.

In order to evaluate the effect of concrete strength shotcrete, 4 models with resistances $150,200,300$ and $400 \mathrm{~kg}$ per square centimeter were made. In figure 21 , the changes in ultimate capacity of the models relative to the concrete strength of shotcrete are calculated by the equation $\mathrm{MF}=0.094 \mathrm{FC}+125.4$, where $\mathrm{ML}$ is the ultimate capacity and FC is shotcrete concrete strength (Naseri.F et al. 2016)

\subsection{Bilateral Shotcrete}

Based on seismic rehabilitation instruction of brick schools, strengthening the brick walls can be done via internal or external faces or a combination of these two (Alireza et al., 2011).

In laboratory samples, one-side strengthening entails displacement in the center of stiffness towards reinforcing layer and thus spinning the samples (Alireza et al., 2011). [(Jaghoobifar, 2008)]. Here to study the effect of this phenomenon, two analytical models strengthened bilateral were made and compared with the analytical sample MWR1. In the sample DMW1 the percent value of cover grid armature of reinforced concrete and reinforced layer thickness with those of samples MWR1 were similar and is divided between the two sides of samples. But on both sides of the wall, the shotcrete layer of the DMW2 sample had similar characteristics to that of the MWR1 sample. Other parameters of materials in the samples were identical. As shown in figure 22, the maximum resistance value and the initial stiffness of the two samples were close. But the in drifts more than $8.0 \%$ (lateral displacement $14 \mathrm{~mm}$ ) because of the torsion of samples, one side is strengthened, and loss of strength in this sample is more severe.

\subsection{Existence of the Opening in Reinforced Samples}

Figure 25 shows how two samples having openings deform in the cases with (RHMW) and without (HMW) reinforcement. In opening samples without reinforcement type-1, the first crack occurred in the corners of the openings in sliding and diagonal form. One side of the wall also acts as a pier in uplift failure mode and in the reinforced samples type-1, despite the strengthened layer, diagonal cracks and sliding in the samples can still be observed implying that we need to reform retrofitting and to make reinforced layer with the more percentage of bar and concrete strength or to rehabilitate the model with two-sided shotcrete.

Figure 23 shows the comparison of force curves relative to the percentage of samples drift RHMW and HMW. According to this curve by improving the wall with a cover layer of reinforced concrete on one side of the wall, the ultimate capacity and displacement corresponding to the ultimate capacity of the sample increase respectively by 2.5 and 2 times. Also the initial stiffness of the sample doubled. One of the main reasons for this increase in amount of the resistance is the break downing a lot of bars at the junction of the wall and foundation and dominance of the uplift in the of sample in the fourth row of reinforced sample relative to sliding in the sample without reinforcing.

Figure 26 shows how the samples with the opening in the case of unreinforced (DHM) and reinforced (DRHM) by the concrete cover deform. As shown, by creating strengthening in this sample, the uplift in one of the piers around the opening with sliding becomes only the uplift failure mode in the entire sample and with the strengthening layer, cracking is not seen in the wall and sample in terms of failure acts as a sample without opening.

Figure 23 shows the comparison of force curves relative to the percentage of samples drift DRHM and DHM. According to this curve by improving the wall with a cover layer of reinforced concrete on one side of the wall, the ultimate capacity of the sample have become respectively 2.8 times. Also the initial hardness of the sample 
doubled. In the sample without reinforcing with $0.55 \%$ drift, when sliding started, drop in the resistance was seen whereas in the reinforced sample due to the ductile failure mode, uplift in the sample as the only failure mode, drop in resistance was not observed even up to $1.5 \%$ drift.

\section{Conclusion}

In this paper the results of numerical models with experimental results related to the rehabilitation of masonry walls with shotcrete with and without opening were validated. The results show that in the studied unreinforced masonry walls, with increasing the vertical stress from the 0.5 to 2 kilograms per square centimeters, the maximum resistance of sample increased by 2.15 times. High growth rate is due to uplift failure mode in the samples.

By modeling a sample having pod with reference sample without pod it became clear that by creating the conditions of confinement, capacity and area under the curve increased approximately 2.78 and 2.6 times, respectively, compared to the unconfined sample. This increase of strength and area under the curve indicates that the pod has a significant effect on increasing the lateral capacity and ductility of brick walls.

By creating openings in the masonry walls first, cracking in corners of opening occured in the form of sliding and diagonal and the ultimate capacity of the samples, with openings window and door is respectively reduced by 12 and 25 percent and loss of strength occurs in the sample with openings window in the less deformations compared to without openings.

By constructing the reinforced models we found that the ultimate capacity becomes 2.4 and 1.6. Also by changing the dimensions of the spring of cover grid of reinforced concrete in the studied area, the overall shape of the curve and their failure in the samples are similar and in the form of uplift failure mode.

By comparing the samples whose shotcrete bar percentage ratio of was half, its ultimate capacity ration was 1.4. Also by improving the reinforced model with opening windows the ultimate capacity and displacement corresponding to the ultimate capacity of the samples increased by 2.5 and 2 times, respectively, compared to the sample having openings without reinforcement. The initial stiffness of the sample doubled.

By improving the reinforced model with the openings in the existence of strengthening layer, cracking is not observed in the wall and the sample in terms of failure acts as a sample without openings. Also the ultimate capacity and initial stiffness of sample increased by 2.8 and 8.1 times respectively.

\section{References}

Abrams, D., Smith, T., Lynch, J., \& Franklin, S. (2007). Effectiveness of Rehabilitation on Seismic Behavior of Masonry piers. Journal of Structureal Enineering, 133, 1(32), 32-43. https://doi.org/10.1061/(ASCE)0733-9445(2007)133:1(32)

Alcocer, S. M., Ruiz, J., Pineda, J. A., \& Zependa, J. A. (1996). Retrofitting of Confined Masonry Walls With Welded Wire Mesh. In: 11th World Conference on Earthquake Engineering, Acapulco, Mexico, Paper No. 1471.

Alireza, M. et al. (2011, May). Country Report on Retrofit Procedure of School Buildings in Islamic Republic of Iran. The Head of Rehabilitation Schools Office.

Darbhanzi, A., Marefat, M. S., \& Khanmohammadi, M. (2014). Investigation of in-plane seismic retrofit of unreinforced masonry walls by means of vertical steel ties. Construction and Building Materials, 52(2014) 122-129. https://doi.org/10.1016/j.conbuildmat.2013.11.020

Gambarotta, L., and Lagomarsino, S. (1997, Aprill). Damage model for the seismic response of brack masonry shear alls. Part I: The mortar joint model and its application. Journal of Earthquake Engineering and $\begin{array}{lll}\text { Structural Dynamics, } & \text { 26(4), }\end{array}$ https://doi.org/10.1002/(SICI)1096-9845(199704)26:4<423::AID-EQE 650>3.0.CO;2-\#

Keykhah, H.,Dadashzadeh,B .(2017) Evaluation ofSediment Distributionin Dams Using theArea-Reduction Empirical Method (Case Study: Cham GardalanDam, Ilam), Journal of Innovative Research in Engineering Sciences, 3(16-20).

Ghiassi, B., Soltani, M., \& Tasnimi, A. A. (2012). A simplified model for analysis of unreinforced masonry shear walls under combined axial, shear and flexural loading. Engineering Structures, 42(September 2012), 396-409. https://doi.org/10.1016/j.engstruct.2012.05.002.

Gostic, S., \& Zarnic, R. (1999). Cyclic response of masonry infilled RC frames and confine masonry walls. Proceeding of the eight North American masonry conference, Austin, Texas, USA, 477-488 
Hashimoto, R., Koyama, T., Kikumoto, M., Saito, T., \& Mimura. M. (2014). Stability Analysis of Masonry Structure in Angkor Ruin Considering the Construction Quality of the Foundation. Journal of Civil Engineering Research, 4(3A), 78-82. https://doi.org/10.5923/c.jce.201402.13.

Jaghoobifar, A. (2008). Studying the behavior of the brick walls reinforced by steel grid and concrete overlay by laboratory and analytical methods. (Master thesis of Earthquake-Civil Engineering) Civil Engineering and Environment Department, Tarbiat Modarres University. (in Persian)

Lourenco, P. B. (1994). Analysis of Masonry Structures with Interface Elements. Delft University of Technology. Retrieved from http://www.csarmento.uminho.pt/docs/ncr/de_civil/1994_Lourenco.pdf

Okamura, H., \& Maekawa, K. (1991). Nonlinear Analysis and Constitutive Models of Reinforced Concrete. Giho-do Press, Tokyo.

Naseri, F., Irani, M., \& Dehkhodarajabi, M. (2016). Effect of graphene oxide nanosheets on the geotechnical properties of cemented silty soil. Archives of Civil and Mechanical Engineering, 16(4), 695-701.

Page, A. W. (1978). Finite element model for masonry. ASCE Journal of the Structural Division, 104(8), 1267-1285. Serial Information: Journal of the Structural Division, 1978, 104(8), 1267-1285.

Yanez, F., Astroza, M., Holmberg, A., and Ogaz, O. (2004). Behavior of confined masonry shear walls whit large openings. 13th World Conf. on Earthquake Engineering. No. 3438.

\section{Appendix A}

\section{Tables}

Table 1. Specifications the reinforced walls covered with reinforced concrete (Jaghoobifar, 2008)

\begin{tabular}{|c|c|c|c|c|c|c|c|c|c|c|c|c|c|c|c|c|}
\hline \multirow[b]{3}{*}{ Wall } & \multirow{2}{*}{\multicolumn{5}{|c|}{ Masonry Wall }} & \multicolumn{11}{|c|}{ Retrofit Detail } \\
\hline & & & & & & \multicolumn{2}{|c|}{ Concrete } & \multicolumn{5}{|c|}{ Vertical Reinforcement } & \multicolumn{4}{|c|}{ Horizontal Reinforcement } \\
\hline & $\begin{array}{c}\text { Length } \\
(\mathrm{cm})\end{array}$ & $\begin{array}{l}\text { Heigth } \\
(\mathrm{cm})\end{array}$ & $\begin{array}{l}\text { Thick. } \\
(\mathrm{cm})\end{array}$ & $\underset{(\mathrm{kg} / \mathrm{cm} 2]}{\mathrm{fm}}$ & $\begin{array}{c}\text { Axial Load } \\
(\mathrm{kg})\end{array}$ & $\begin{array}{l}\text { Conc. } \\
\text { Thick. } \\
(\mathrm{cm})\end{array}$ & $\begin{array}{c}\mathrm{fc} \\
(\mathrm{kg} / \mathrm{cm} \mathrm{c})\end{array}$ & $\mathbf{p}$ & $\begin{array}{c}\text { Ast } \\
\left(\mathrm{cm}^{2}\right)\end{array}$ & $\begin{array}{c}\text { Diam. } \\
(\mathrm{cm})\end{array}$ & $\begin{array}{l}\text { Dist. } \\
(\mathrm{cm})\end{array}$ & $\begin{array}{c}\mathrm{fy} \\
(\mathrm{kg} / \mathrm{cm} 2)\end{array}$ & $\rho$ & $\begin{array}{l}\text { Diam. } \\
(\mathrm{cm})\end{array}$ & $\begin{array}{l}\text { Dist. } \\
(\mathrm{cm})\end{array}$ & $\begin{array}{c}\mathrm{fy} \\
(\mathrm{kg} / \mathrm{cm} 2)\end{array}$ \\
\hline SSBW2 & 180 & 80 & 20 & 50 & 6000 & 4 & 280 & 0.0063 & 4.536 & 0.4 & 5 & 3096 & 0.0063 & 0.4 & 5 & 3096 \\
\hline DSBW2 & 180 & 80 & 20 & 50 & 6000 & 4 & 280 & 0.0063 & 4.536 & 0.4 & 5 & 3096 & 0.0063 & 0.4 & 5 & 3096 \\
\hline SSBW1 & 180 & 120 & 20 & 50 & 4000 & 4 & 280 & 0.0028 & 2.016 & 0.4 & 10 & 6500 & 0.003 & 0.4 & 10 & 6500 \\
\hline DSBW1 & 180 & 120 & 20 & 50 & 4000 & 4 & 280 & 0.0028 & 2.016 & 0.4 & 10 & 6500 & 0.003 & 0.4 & 10 & 6500 \\
\hline
\end{tabular}

\section{Appendix B}

\section{Figures}

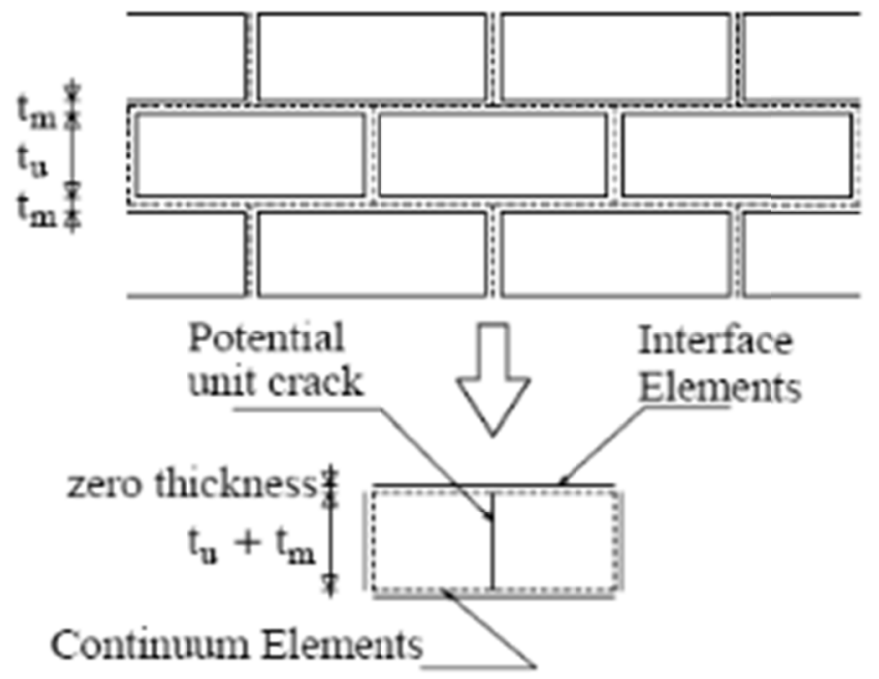


Figure 1. Simplified models of Lorenzo (Okamura and Maekawa, 1991)

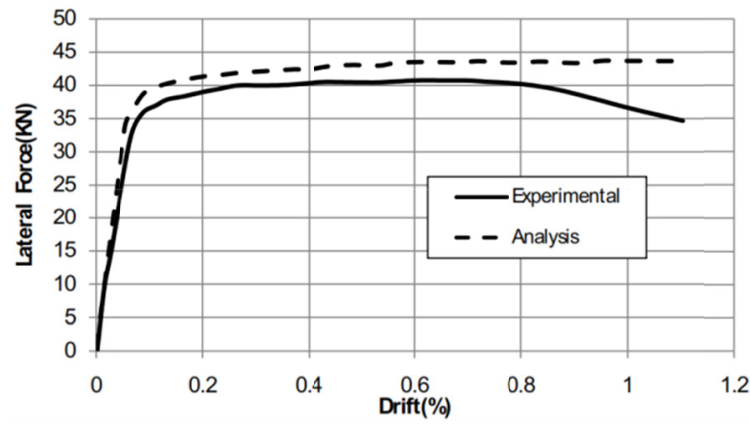

Figure 2. Comparison of the behavior curve of laboratory sample and analytical model

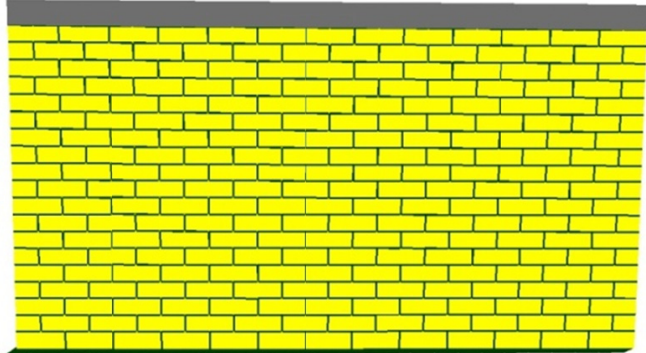

(b)

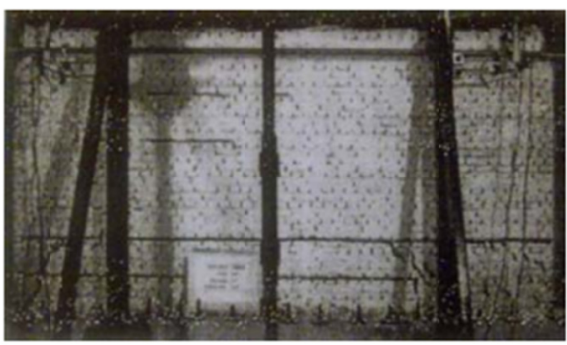

(a)

Figure 3. a) way of prototype cracking (Darbhanzi, Marefat and Khanmohammadi, 2014), b) way of numerical model cracking
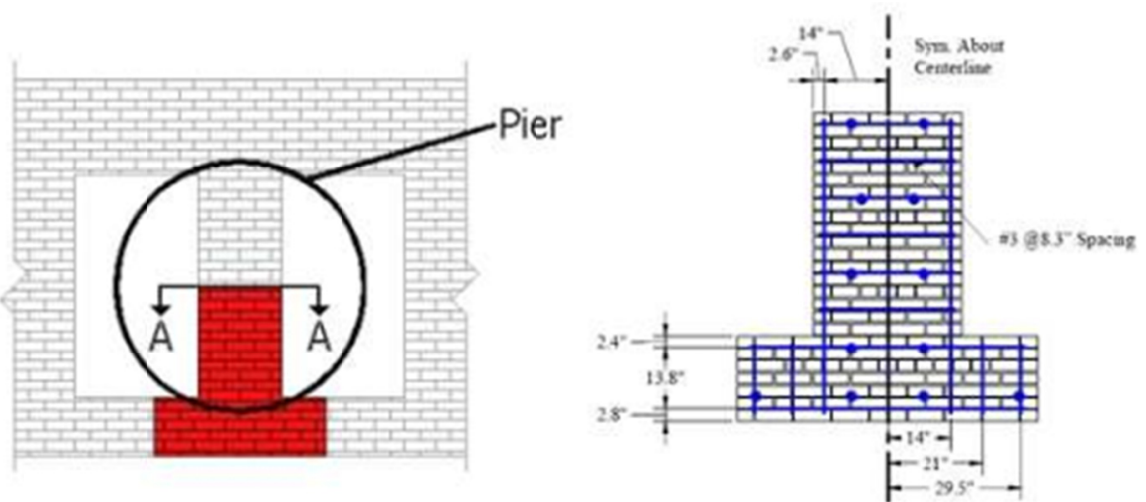

Figure 4. sample of reinforced with shotcrete (Abrams, Smith, Lynch and Franklin, 2007)

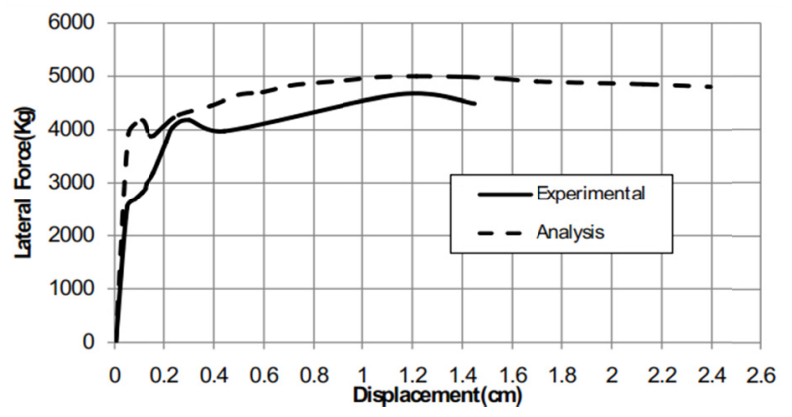

(b)

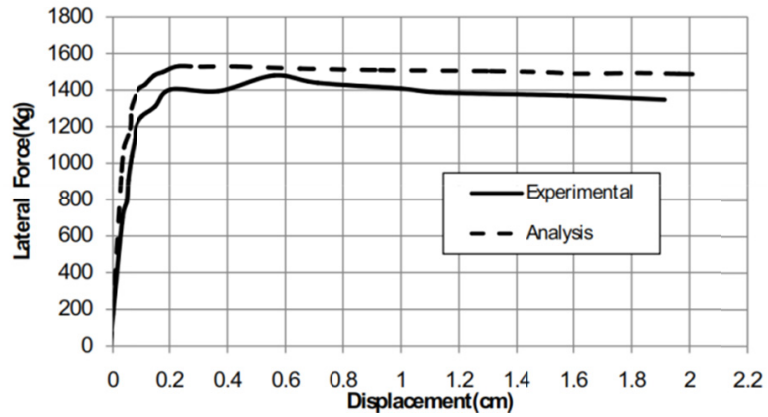

(a)

Figure 5. comparing analytic and laboratory results a) unreinforced brick foundation F1, b) the reinforced 
brick foundation $\mathrm{F} 4$

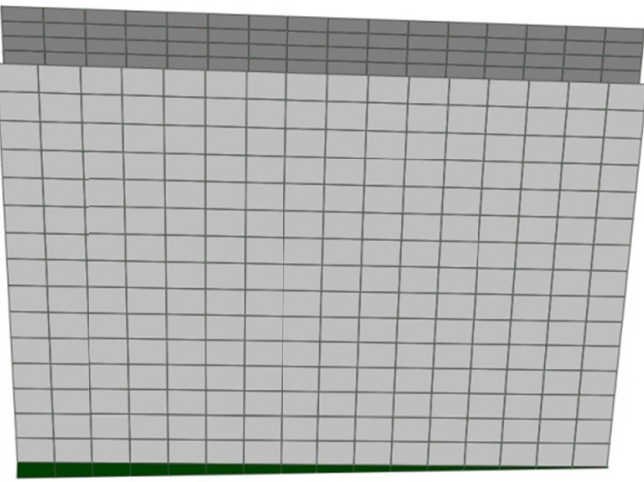

(b)

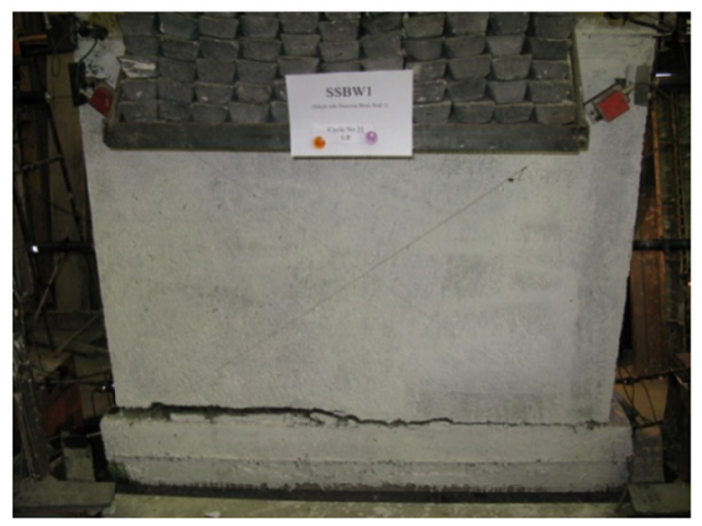

(a)

Figure 6. a) way of failure of laboratory sample SSBW1 (Jaghoobifar, 2008), b) way of deformation of the numerical model SSBW1

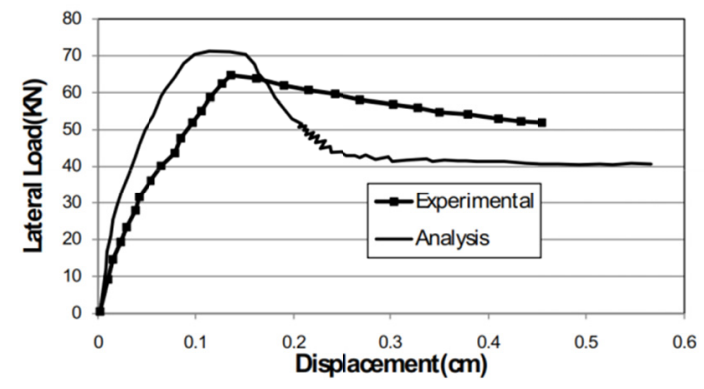

Figure 7. Comparing analytic and laboratory sample SSBW1

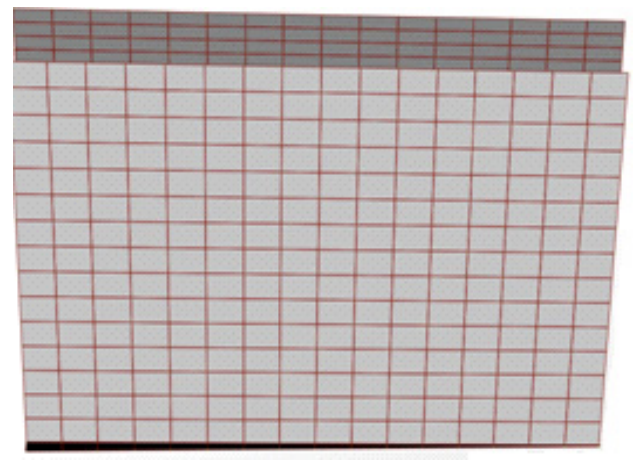

(b)

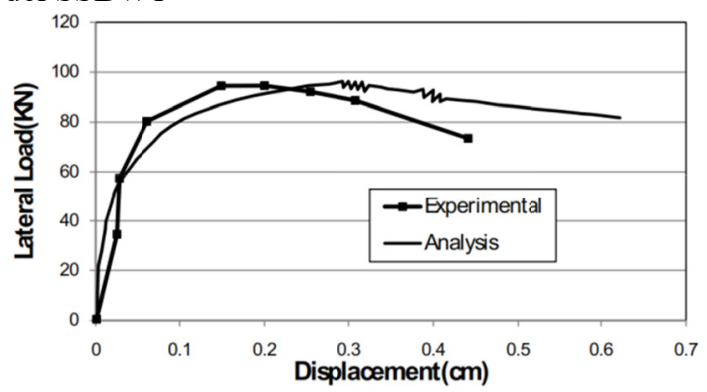

Figure 8. Comparing analytic and laboratory sample BSBW1

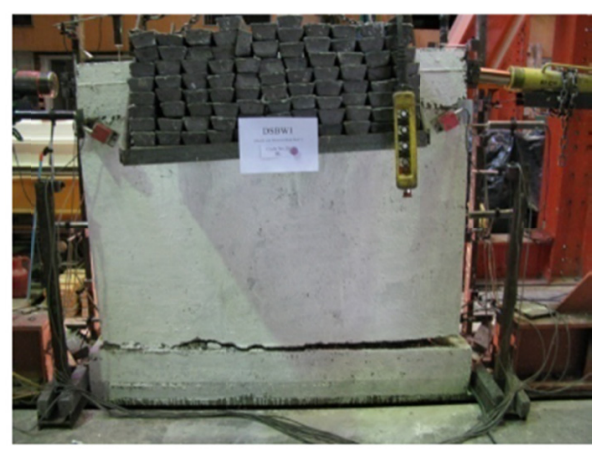

(a)

Figure 9. a) way of failure of laboratory samples DSBW1 (Jaghoobifar, 2008), b) way of deformation of the numerical model DSBW1

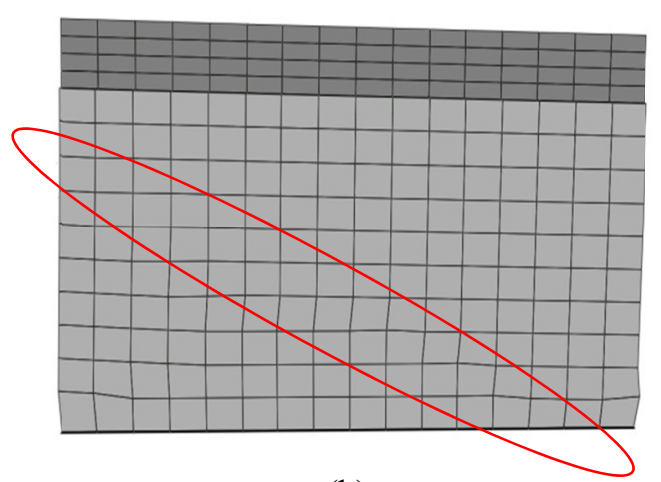

(b)

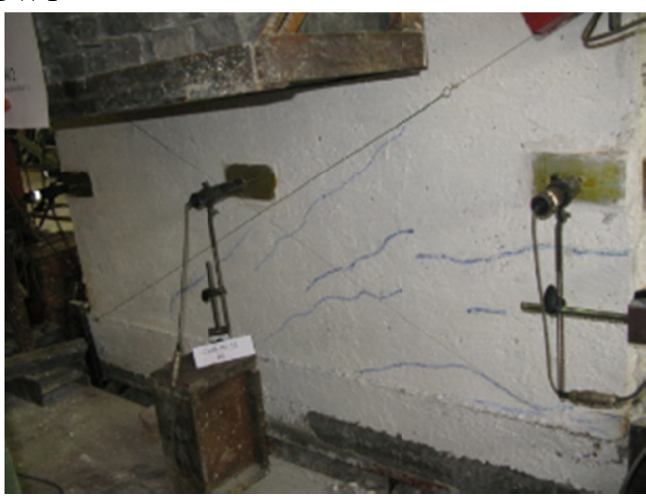

(a) 
Figure 10. a) way of failure of laboratory samples SSBW2 (Jaghoobifar, 2008), b) way of deformation of the numerical model SSBW2

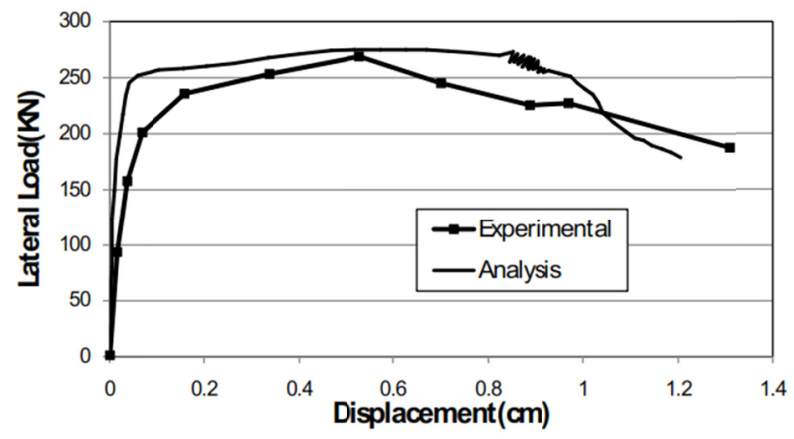

(b)

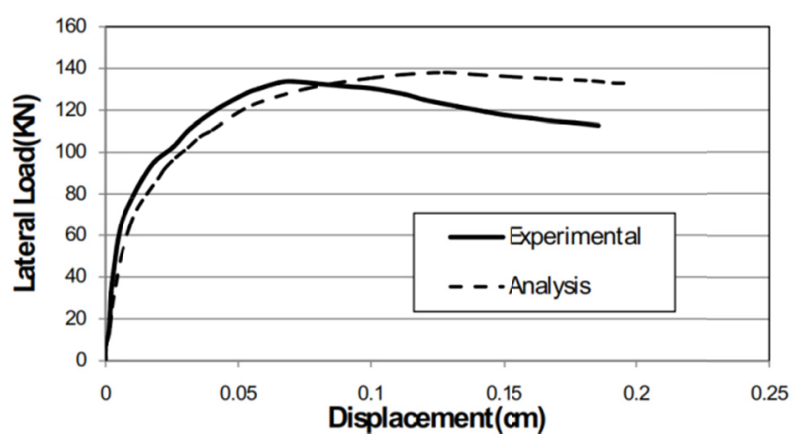

(a)

Figure 11. Comparing analytic and laboratory results of a)sample SSBW2 b) DSBW2

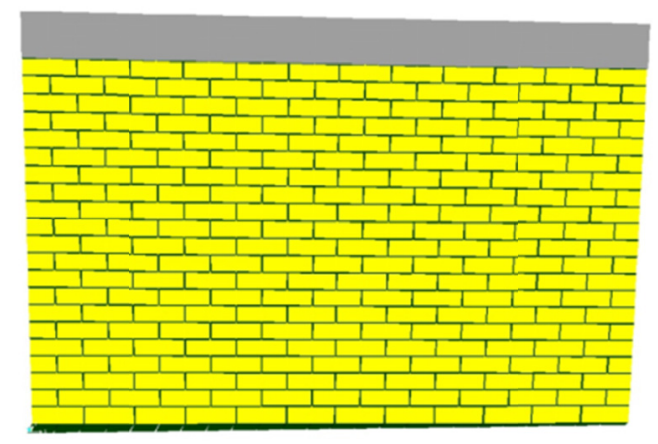

(a)

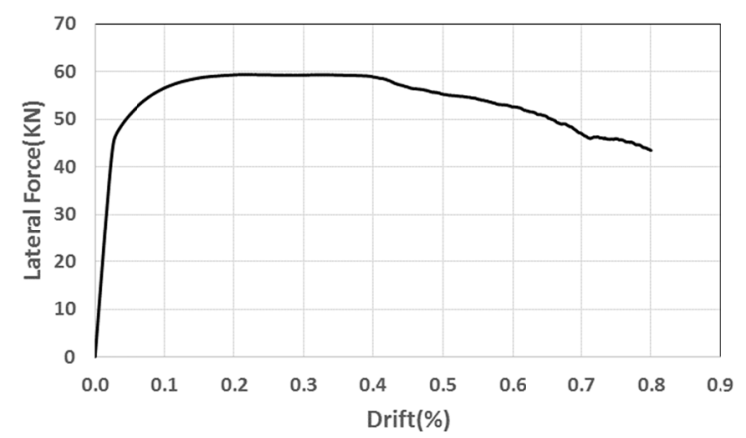

(b)

Figure 12. a) diagram of force drift-sample b) Schematic of the sample deformation in the drift 0.8 percent model RMW1 RMW1

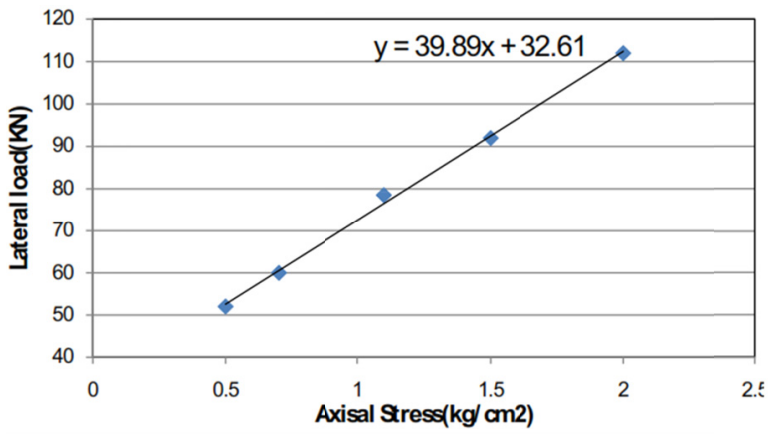

(b)

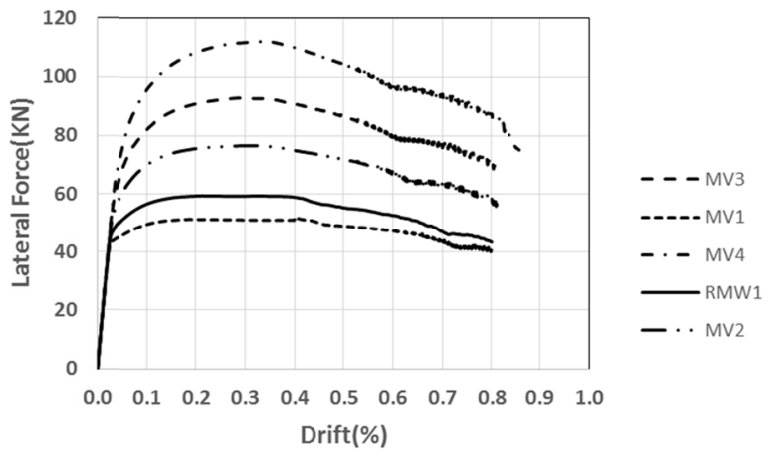

(a)

Figure 13. a) The force curve of lateral-drift samples to evaluate the effect of gravitational load, b) an almost linear relations of the final capacity with respect to the gravity load increase of the studied brick samples 


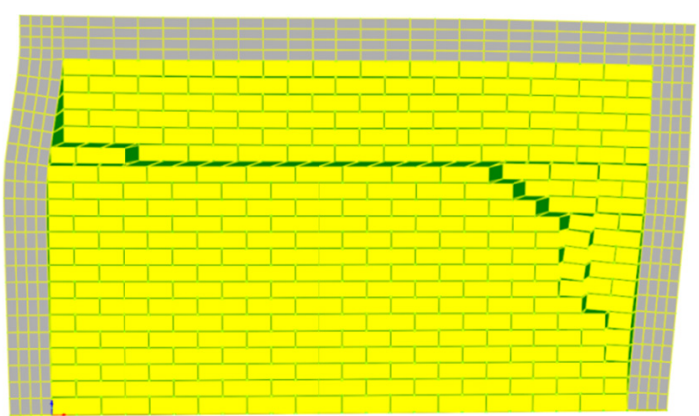

(b)

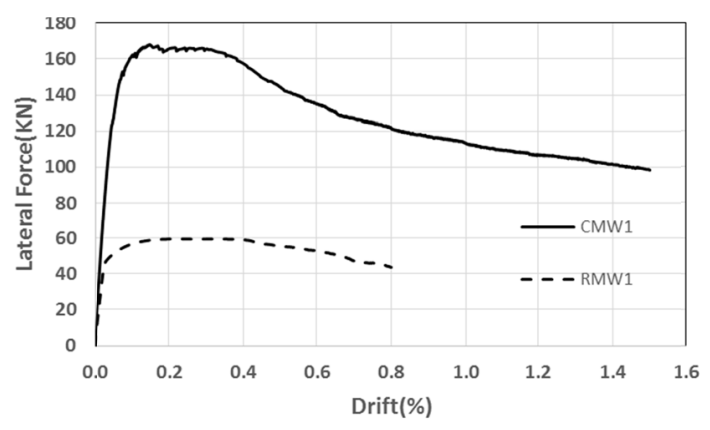

(a)

Figure 14. a) comparing the lateral force curve against the drift of samples CMW1 and RMW1, b)Schematic of the sample deformation in the CMW1

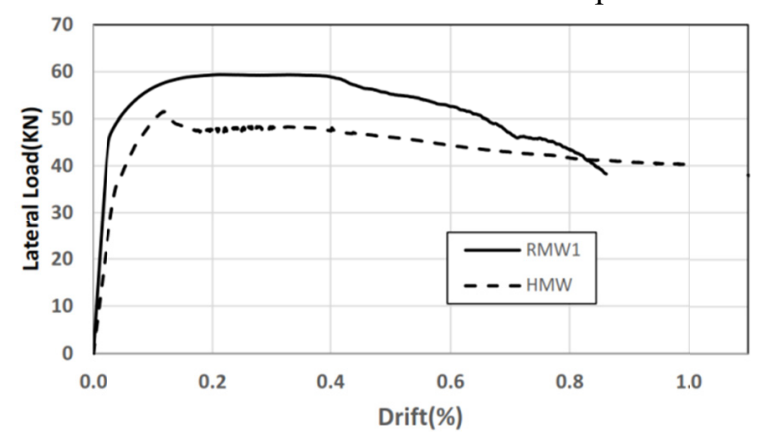

(b)

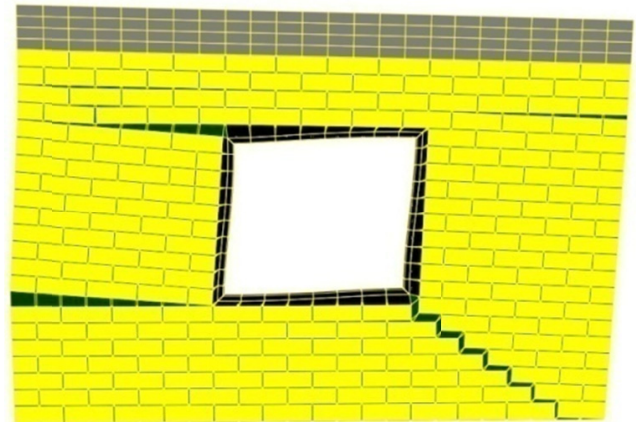

(a)

Figure 15. a) comparing the lateral-drift force of samples HMW and RMW1 b) Schematic of cracking of the model HMW

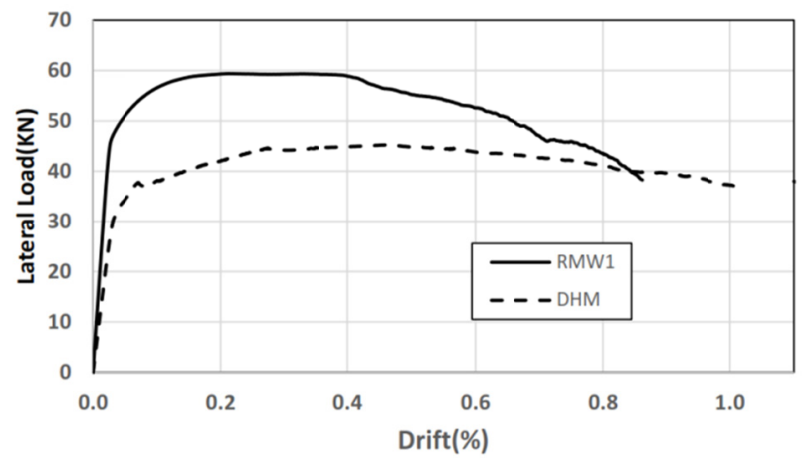

(b)

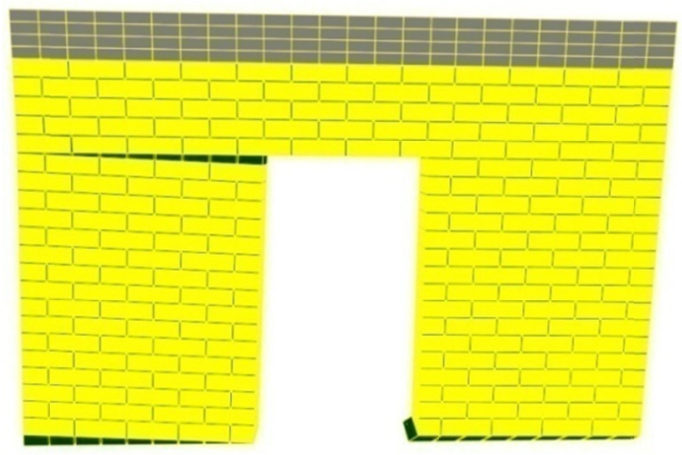

(a)

Figure 16. a) comparing the lateral-drift force of samples DHN and RMW1 b) Schematic of cracking of the model DHM

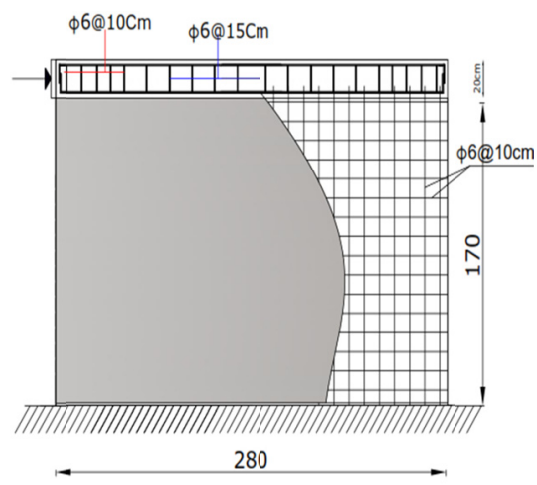

Figure 17. wall facing a) MWR1 b) MWR2

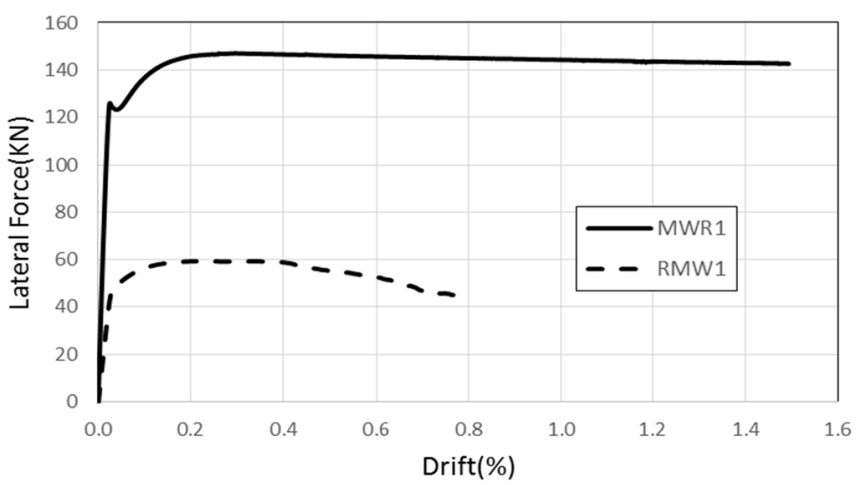

Figure 18. diagram of force with respect to the sample drift 


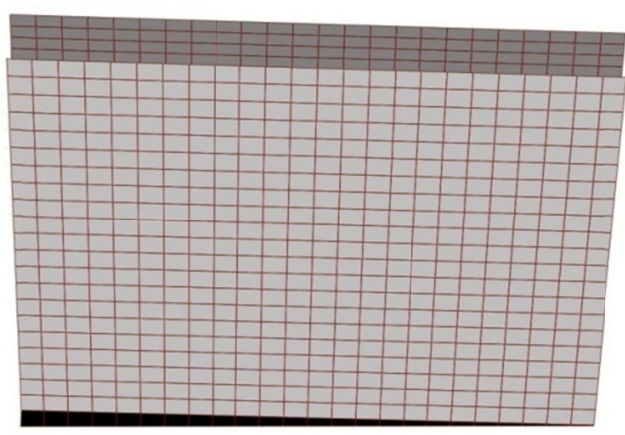

(b)

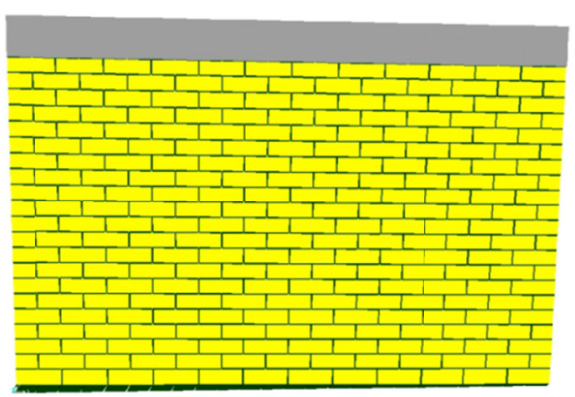

(a)

Figure 19. Schematic of sample deformation, a) RMW1 b) MWR1

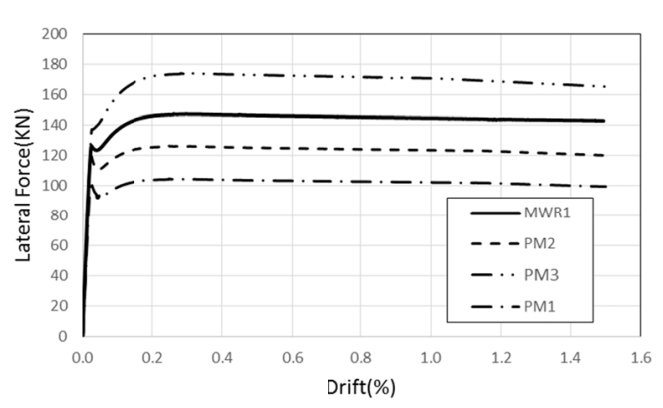

Figure 21. Effect of dimensions of the armature grid of reinforced concrete cover layer

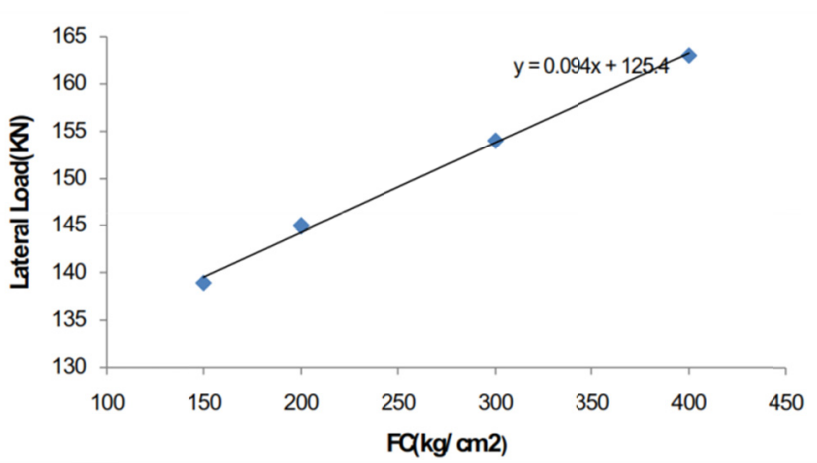

Figure 20. Effect of concrete strength of reinforced concrete cover layer

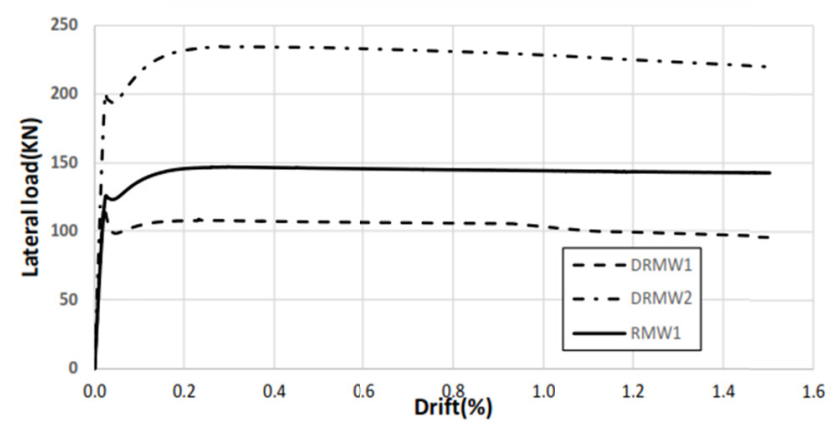

Figure 22. The force curve with respect to the drift in order to evaluate the effect of bilateral shotcrete

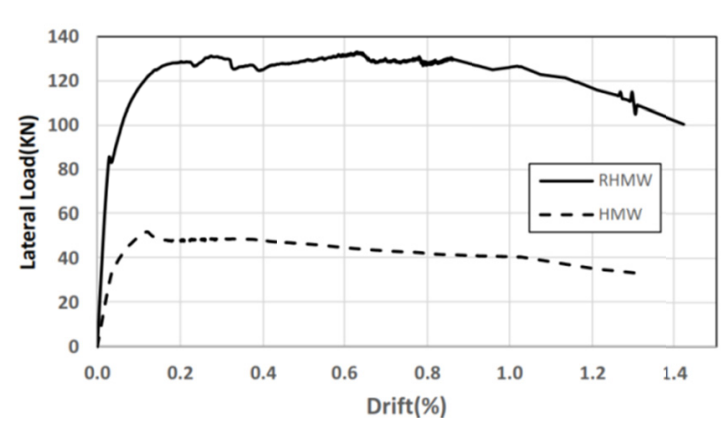

Figure 23. The force curve with respect to the drift in order to evaluate the effect of presence of opening window

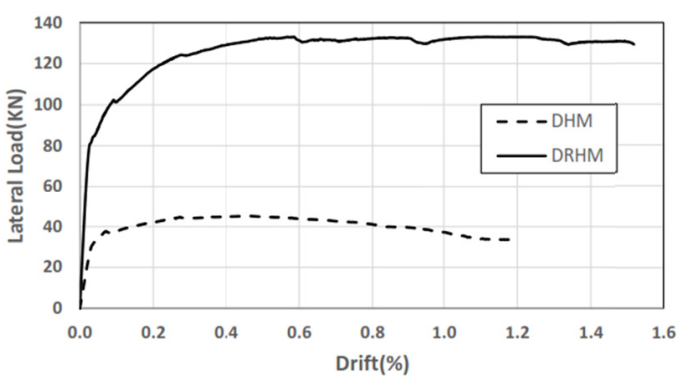

Figure 24. The force curve with respect to the drift in order to evaluate the effect of presence of opening door 


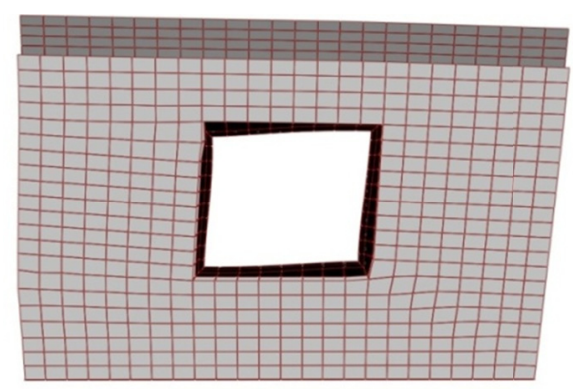

(b)

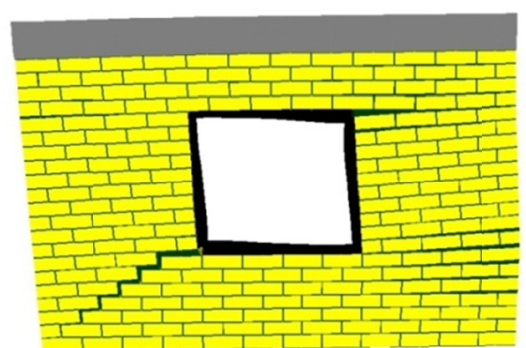

(a)

Figure 25. Schematic of sample deformation a) RMW1 b) DRHM

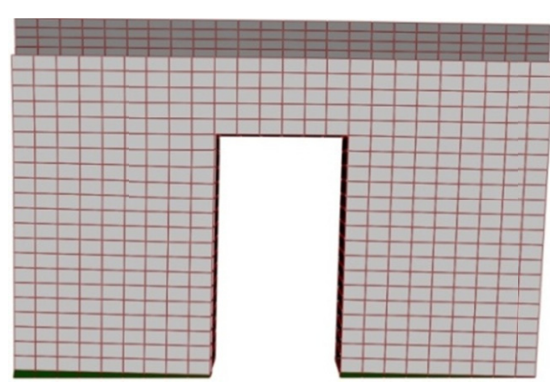

(b)

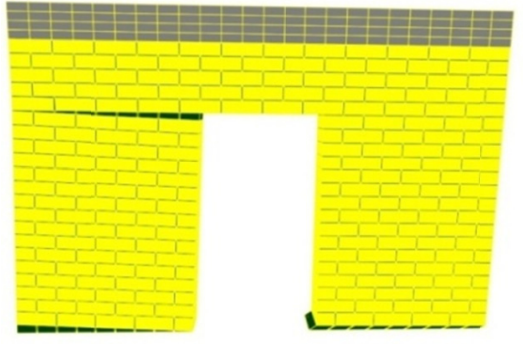

(a)

Figure 26. Schematic of sample deformation, a) RMW1 b) DRMM

\section{Copyrights}

Copyright for this article is retained by the author(s), with first publication rights granted to the journal.

This is an open-access article distributed under the terms and conditions of the Creative Commons Attribution license (http://creativecommons.org/licenses/by/4.0/). 